In Philosophy (2020), vol 95 issue 2.

\title{
Jake Wojtowicz \\ Todd May, A Decent Life: Morality for the Rest of Us, Chicago and London: University of Chicago Press, 2019, 212pp., \$25.00/£19.00 (hardback), ISBN 978-0-226-60974-4.
}

Morality demands of us that we maximise the good, or do only that which can be universalised, or perfectly exemplify the virtues. According to Todd May in A Decent Life, the moral theories of contemporary philosophy demand adherence to a perfect standard, they demand what May calls 'altruism' (16). Anything that falls short is a failure even if some failures are worse than others. Moral theories might demand perfection yet offer us some encouragement to at least avoid abject failure.

A Decent Life is not a book about how to fail well; rather, it is a book about how to live a morally decent life, where this life is not measured by the perfect standards of altruism. May does not level down from the perfect moral life, he starts from the decent moral life (20-23). One might think that this is a lesser life than the altruistic life but May offers an alternative characterisation: we need not think of this sort of life as lesser, but as 'other' $(20,27)$. This difference is important. It is the difference between a tennis manual that measures us all by the standards of Roger Federer, seeing everything that falls short as a failure, and a tennis manual that starts from-and appreciates-the value of good tennis played well.

Before exploring why altruism troubles May and what he offers as an alternative, it is important to point out that $A$ Decent Life is different in another way from much contemporary moral philosophy: it is far less fastidious. May's style mirrors his content. Much as moral theories demand perfection, analytic philosophy sometimes is taken to demand of us a watertight theory immune to all possible objections, fleshed out to take account of each possible misunderstanding. We move from Theory to Theory ${ }^{k}$, from the brief and the plausible to the arcane and labyrinthine. May's style is breezy, conversational, and compelling. And it is not based on faith in all-encompassing principles: although they can help, a decent life can only ever be guided by rules and instead requires some degree of imagination and the wisdom to navigate the situations that confront us (66-7).

The lack of fastidiousness is, all things considered, a very good thing. But it has a downside: some issues seemed to be under-discussed or a little one-sided. For instance, May says that one of the main problems for utilitarianism is that it allows room for 'moral luck', that we can do the right thing (or the wrong thing) through 'sheer contingency' (6). The utilitarian isn't given any right of reply, and it's far from clear that moral luck is what will sink utilitarianism. Still, May is not in the business of 'decisive refutations' (8), and he certainly provides 
enough problems ('quirks', as he calls them) for traditional moral theories-by which he means utilitarianism, deontology, and virtue theory-to motivate his own project.

May offers these quirks to show that it is hard to move from the "simple form" of the major moral theories towards "moral practice" (8), but his overarching problem is shared by all of these theories and is threefold. Firstly, they require us to make great sacrifices in order to help others live meaningful lives, but these theories demand that we sacrifice the things that make our lives meaningful (15-16). Maybe there is a reply available here: certain goods make our lives meaningful, but altruism does not demand that we sacrifice a meaningful life, just that we find different ways of living a meaningful life. Although he doesn't explicitly address this objection, May's second point tells against it. Some of our projects-excesses from altruism's point of view-make life more valuable: the works of Van Gogh or Beethoven brighten our lives even if altruism forbids them (17). A world beholden to morality would be 'leeched of many of its hues' (18). Thirdly, most of us are incapable of living up to the standards altruism sets, yet still we want to live morally good lives (19). So, May sets out to offer a picture of a decent life rather than an altruistic one.

Though he rejects the extremes of altruism, May does not set out just to vindicate our current practices but to offer a picture that encourages us to demand more of ourselves $(29,80)$. He thinks we can do this by starting from a central idea: 'there are others in the world who have lives to live' (29). We act decently when we recognise this and seek 'to incorporate that recognition into our lives in ways that are reasonably workable' (49). Although our behaviour might not be altruistic, it might still be decent: we might fail to act in a way that, say, maximises the good, yet still act in a way that respects others as people with their own lives, projects, and values.

May expounds this through the rest of the book. In Chapter 2 he focusses on how we should be decent to those around us; Chapter 3 looks to those distant from us, either in time or in space; Chapter 4 considers animals; Chapter 5 looks at the political sphere. The concluding chapter reinforces the idea that others have lives to live, lives that are often more complicated than we might recognise. It is interesting and compelling: May works from how we are less perceptive about ourselves than we might think, drawing us towards the recognition that others, too, are deeper than we might first realise; alongside this, he discusses what it means to see a life-our own lives or the lives of others-as valuable.

Part of May's approach is to offer examples of decent behaviour. From the Jewish person who invited a white nationalist to dinner in order to foster mutual recognition (35-37), to the indigenous groups who personalize the animals they eat and thank the animals through rituals (131), May's examples illustrate the various ways in which we might behave decently. This has a vividness that eludes much of moral philosophy. By showing us how people can be decent, May makes his point lucidly clear. Alongside this, he discusses the moral issues that arise when we think about how to be decent. His discussion of why we 
need to be decent to people who live far away was clear and persuasive: we will impact their lives but our relationship with them is more tenuous so decency demands less than it demands of our interactions with those closer to us. His discussion was also clear when he argued that the fact animals have lives to live and can suffer compels us to treat them decently (129).

I felt that occasionally May spends too much time discussing problems from contemporary moral philosophy that he elsewhere wants to leave behind. Here is one instance. May considers people who will come to exist in the future and asks: 'if future people do not exist, how can we have some sort of moral relationship with them? How can we express ourselves morally to people who are not there?' (91). There clearly will be people, and our actions will affect their lives-it's obvious that if we use up the world's resources future people will have nothing left-surely, we either respect future people by leaving them sufficient resources, or we do not. May seems to say as much himself (92). But, a few pages later, May notes that which particular people come to exist depends upon what we do now. If we act differently, we give rise to different people (97). Thus, those who are born a few centuries hence aren't able to complain that we ruined the planet for them because had we not ruined the planet they would not exist.

May is right that this shows 'everything we do has the potential to affect [future people], even to the very question of who will exist.' (98). What isn't clear is whether the fact that we can affect who will exist matters aside from illustrating the fairly obvious point that our actions affect future generations. The intriguing aspects of this problem seem to be raised and then dropped. Further, contrary to what May suggests, it's far from clear that the fact future people can't complain (because they can't resent the actions that were necessary for their existence) turns our "morally inadvisable act... into a morally good act (96). If I wrong you by forgetting to drive you to the airport, you might not be able to coherently complain if the plane you were supposed to be on crashes; still, I wronged you by failing to get you to the airport. ${ }^{2}$ It's not clear to me that this discussion illuminates the idea of a decent life.

May surveys a range of issues and introduces a variety of philosophical discussions. It's no surprise that some will hit the mark and others will miss, and I suspect this is partly down to a reader's own taste and interests. Still, the range of issues that May surveys, and the eloquent way in which he conveys them, makes this book an accessible introduction to some important issues in ethics. Yet it is more than an introduction. May makes a compelling case for his vision of a decent life. More than that, he makes a powerful case for focussing on a decent life rather than just on a perfect one. This book is not perfect, but May is right that the less-than-perfect can still be valuable. His book is a significant contribution to moral philosophy.

\footnotetext{
${ }^{1}$ This problem was originally posed by Parfit, Reasons and Persons, 358.

${ }^{2}$ This is discussed in depth in Wallace, The View From Here, Chapter 3. The plane example occurs at 98-99.
} 